\title{
On relations among perceptual and cognitive measures of information processing
}

\author{
PETER SUEDFELD² AND SILVAN S. TOMKINS, RUTGERS, THE STATE L'NIVERSIT:
} WILLIAM H. TUCKER, PRINCETON L'VIVER SITY

\begin{abstract}
Tests of visual information processing and verbal information processing were administered to $178 \mathrm{Ss}$. Intercorrelations showed low positive relationships between two sets of two cognitive measures each, the Sentence Completion Test (Schroder, Driver, \& Streufert, 1967) and the Interpersonal Topical Inventory (Tuckman, 1965), and the Interpersonal Topical Inventory and the Polarity Scale (1965), and a high negative correlation between preference for highly complex and for moderately complex visual stimuli. Factor analysis showed three reliable major factors. There was little evidence for a relationship between perceptual and cognitive processing characteristics, which indicates some danger for general theorists.
\end{abstract}

Since George A. Miller's famous article on the ability of human beings to process information (1956), a great number of theoretical and experimental papers have used individual differences in this ability as a fundamental dimension in personality, learning, development, and other areas. There have been few attempts to define the "information processing" construct cross-modally, the generality of the dimension being assumed at least implicitly. In practice, however, the tests used to measure these individual differences are highly varied.

Students of perception have used reaction time (Hyman, 1953), contingent uncertainty analysis (Garner \& Hake, 1951), and limits on the flow of information in their attempts to deal with these problems (Gamer, 1962; Munsinger \& Kessen, 1966). Workers interested in the cognitive aspects of information processing, on the other hand, have attempted to write multiple choice and projective tests which differentiate among individuals who have developed simple or complex cognitive structures. The measures used in this study, some of the standard ones in the literature, are described belnw.

\section{COGNITIVE INFORMATION PROCESSING}

\section{Sentence Completion Test}

The SCT was developed to measure conceptual structure, a dimension which characterizes Ss' ability to differentiate and integrate information (Schroder \& Streufert, 1962; Schroder, Driver, \& Streufert, 1967). The simple pole of the continuum is characterized by rigid, hierarchical, stimulus-bound information processing; complex structures in contrast are flexible, integrated, and internally directed. Experiments validating the construct and test-development data are summarized in Schroder et al (1967).

\section{Interpersonal Topical Inventory}

The ITI was designed by Tuckman $(1965,1966)$ to replace the SCT. Instead of open-ended tasks, which are difficult and time-consuming to score, the ITI provides a series of forced-choice items. Each pair of items allows Ss to choose statements which are characteristic of conceptual structures of varying levels of complexity. Four specific levels can be identified from the predominantly chosen responses; the scoring system is based on that originally reported for the SCT (Schroder \& Streufert, 1962).

\section{Polarity Scale}

Tomkins $(1964,1965)$ has described two major orientations toward the world: one, humanistic, relativistic, open, and accepting; the other, normative, restrictive, and absolutistic. These ideologies pervade the individual's cognitive and emotional tendencies, with the result that information is generally processed and interpreted so as to lead to decisions consonant with the person's ideology. The test itself consists of 59 forced-choice pairs. The $\mathrm{S}$ picks the statement with which he agrees: both, neither, humanist, or normative.

\section{Preference}

\section{PERCEPTUAL INFORMATION PROCESSING}

Munsinger and Kessen (1966) have shown that there is a limit on Ss' ability to process information, and that Ss prefer a level of variability at or near this limit. Using a paired-comparison procedure, these investigators demonstrated that Ss show a marked preference for an intermediate amount of variability. Since preference was shown to reflect the ability of Ss to process variability (Munsinger \& Kessen, 1966), there should be a strong negative relation between preference for visual stimuli of intermediate variability (i.e., figures with 5 or 10 turns) and preference for highly variable stimuli (20 and 40 turns).

\section{Perceptual Estimation}

Garner (1962) has argued that when several alternative classes of stimuli are presented and several alternative responses are allowed, the contingent uncertainty between the stimuli and the responses may be taken as a measure of the person's information processing ability. This implies a joint consideration of how of ten $S$ can classify a given set of stimuli into correct categories and of the response biases affecting the probabilities of each category.

Our primary interest in this study was the relationship between the cognitive and the perceptual indices of information processing. We expected that $S s$ who obtain high complexity scores on the SCT and the ITI, and/or a high humanistic score on the Polarity Scale, would be effective information processors in perceptual tasks. They should obtain a higher contingent uncertainty score, and they should also state higher preferences for an intermediate level of variability of random shapes than do Ss with low or normative scores.

Because Vannoy (1965) has shown that the SCT measures an aspect of information processing complexity which is unrelated to other, frequently used tests, we also desired to discover its correlation with the two other cognitive measures (which were not administered in the Vannoy study).

\section{METHOD}

One hundred seventyeight Ss from the introductory psychology classes of the University of Illinois served as Ss in this experiment. These Ss were unsystematically divided into three approximately equal-sized groups. Ss in each group were administered the Sentence Completion Test, the Interpersonal Topical Inventory, the Polarity Scale, the preference for variability measure, and the tachistoscopic estimation task. Instructions and scoring for each of the procedures were exactly as outlined in their respective manuals or puhti-hed reports.

On the perceptual tasks, 5-, 10-, 20- and 40-turn rundom shapes were presented at tachistoscopic durations $(100 \mathrm{msec})$. 
They were first shown paired, and Ss were asked to choose the preferred form. Next, single forms were presented in a counterbalanced order. The Ss were asked to judge whether the presented random shape contained $5,10,20$, or 40 turns. Contingent uncertainty was calculated for the classification of each of the four sets of shapes.

\section{RESULTS}

The correlation matrix (Table 1) indicates a highly significant negative correlation between high- and moderatecomplexity preference, and a significant positive relationship between the SCT and its objective version, the ITI. No other correlation reached significance although the positive PolarityITI and SCT-Moderate Preference correlations implied strong trends.

Four varimax factor analysee were performed on these data. They included separate analyses for each third of the Ss $(N=$ 60. 60, and 53), and for all Ss (see Table 2). The varimax factor analysis solution for each of the groups of Ss reliably showed that approximately $90 \%$ of the total variance may be explained by three factors. The loadings of the tasks on the first factor showed a cluster which consisted of preference for an in termediate level of varipbility (20-40 turns). The second factor included the SCT and the ITI; the third showed a clustering of the ITI and the Polarity Scale.

\section{DISCUSSION}

In general, the reliability of our findings over the three separate groups of Ss (as replication) was good. Relations between the perceptual scores were as expected: Ss who preferred low variability figures strongly rejected figures of higher variability. The preference for a given level of perceptual complexity is apparently a consistent characteristic. Ability to process visual information did not appear strongly on any factor and was not significantly correlated with complexity preference. The cognitive tests did show some clustering, but there was only slight evidence for a relationship between the perceptual and the cognitive variables. The projective Sentence Completion Test, and an objective version of that test (the Interpersonal Topical Inventory), while highly correlated with each other, did not yield a common cluster with the other three measures; the two conceptual complexity tests seem to reflect a different type of information processing (see also Vannoy, 1965). Three replications of a pattern of interrelations add confidence that the measures are related in a reliable manner.

The cognition research of Tomkins $(1964,1965)$ and of Schroder et al (1967) has typically involved sequences of stimuli which must be transformed in a complex solution. The perceptual tasks in this study were much simpler discrimination situations. Our findings emphasize the importance of clearly labeling constructs, in order to avoid confusion among the many current approaches to information processing. While there are some known relationships between perceptual and cognitive characteristics (e.g., Barron, 1953; Witkin, Lewis,

Table 1

Correlation Matrix

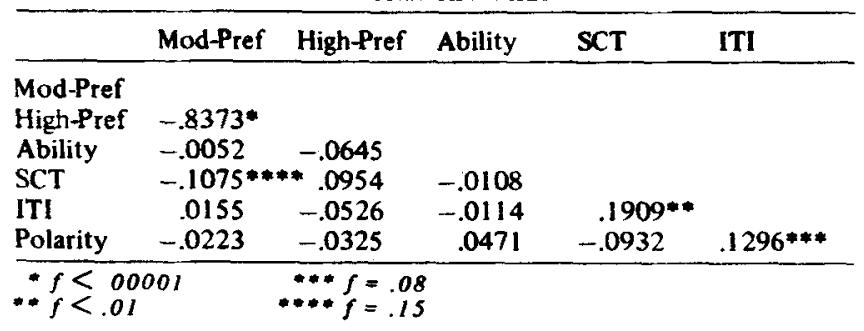

Table 2

Output Matrix from Varimax Factor Analysis of All Ss

\begin{tabular}{lrrr}
\hline \multicolumn{1}{c}{ Tasks } & \multicolumn{3}{c}{ Factors } \\
& \multicolumn{1}{c}{2} & \multicolumn{1}{c}{3} \\
\hline Pref. Intermed. Complexity & -.766 & -.057 & -.016 \\
Pref. High Complexity & 1.000 & .006 & .043 \\
Visual Processing Ability & -.031 & -.010 & .042 \\
Sentence Completion & .084 & .527 & -.134 \\
ITI & -.042 & .359 & .226 \\
Polarity & .005 & -.006 & .358 \\
\hline
\end{tabular}

Hertzman. Machover, Meissner, \& Wagner, 1954), it is clear that no general correspondence between the two realms of behavior has been established. Until such a bridge is built, theorists will find it difficult to formulate a unitary construct of "information processing" (see Schroder \& Suedfeld, in press).

\section{REFERENCES}

BARRON, F. Complexity-simplicity as a personality dimension. Journal of Abnormal \& Social Psychology, 1953, 48, 163-172.

GARNER, $W$. R. Uncertainty and structure as psychological concepts. New York: Wiley, 1962.

GARNER, w. R., HAKE, H. W. The amount of information in absolute judgments. Psychological Review, 1951, 58, 446-459.

HYMAN, $R$. Stimulus information as a determinant of reaction time. Joumal of Experimental Prychology, 1953, 45, 188-196.

MILLER, G. A. The magical number seven, plus or minus two: Some limits on our capacity for processing information. Psychological Review, 1956, 63, 81-97.

MUNSINGER, H., \& KESSEN, W. Uncertainty, structure, and preference. Psychological Monographs: General \& Applied, 1964, 78 (Whole No. 586), 1-24.

MUNSINGER, H., \& KESSEN, W. Stimulus variability and cognitive change. Psychological Review, 1966, 73, 164-178.

SCHRODER, H. M., DRIVER, M. J., \& STREUFERT, S. Human information processing. New York: Holt, Rinehart, Winston, 1967.

SCHRODER, H. M., \& STREUFERT, S. The measurement of four systems varying in level of abstractness (sentence completion method). ONR Technical Report, 1962, No. 11.

SCHRODER, H. M., \& SUEDFELD, P. (Eds.) Personality. Information processing models. New York: Ronald Press, in press.

TOMKINS, S. S. Polarity scale (4th Ed.). New York: Springer, 1964.

TOMKINS, S. S. Affect and the psychology of knowledge. In S. S. Tomkins and C. E. Izard (Eds.), Affect, cognition and personality: Empirical studies. New York: Springer, 1965. Pp. 72-97.

TUCKMAN, B. W. Integrative complexity and attitudinal orientation Perceptual \& Motor Skills, 1965, 21, 838.

TUCKMAN, B. W. Integrative complexity: Its measurement and relation to creativity. Educational \& Psychological Measurement, 1966:'26, 369-382.

VANNOY, J. S. Generality of cognitive complexity-simplicity as a personality construct. Journal of Personality \& Social Psychology, $1965,2,385-396$.

WITKIN, H. A., LEWIS, H. B., HERTZMAN, M., MACHOVER, K., MEISSNER, P. B., \& WAGNER, S. Personality through perception: An experimental and clinical study. New York: Harper, 1954.

\section{NoTES}

1. Data collection was conducted during the first author's tenure as Visiting Assistant Professor at the University of Illinois, and was supported by the University of Illinois Research Board. The later preparation of the manuscript was aided by a grant from the Rutgers University Research Council. Harry Munsinger conducted the administration and scoring of the perceptual tasks. The advice of B. P. Indik and S. J. Messick (and the support of the Educational Testing Service) in analyzing the data are gratefully acknowledged.

2. Address: Department of Psychology, Rutgers, The State University, New Brunswick, New Jersey 08903.

(Accepted for publication Decem her 13, 1968.) 